\title{
Structural relations of brain- behavioral systems and emotion regulation difficulties with craving of marijuana in students
}

\author{
Negar Memarpour Asiaban ${ }^{1}$, Saeed Imani ${ }^{2}$, Omid Shokri ${ }^{3}$ \\ 1-Master Student of Clinical Psychology, Department of Clinical and Health Psychology, Shahid Beheshti \\ University, Tehran, Iran. \\ 2- Assistant Professor, Department of Clinical and Health Psychology and Department of Counseling, Shahid \\ Beheshti University, Tehran, Iran (Corresponding Author). \\ E-mail: s_imani@sbu.ac.ir \\ 3- Assistant Professor, Department of Educational and Development Psychology, Shahid Beheshti University, \\ Tehran, Iran.
}

Received: 18/11/2019

Accepted: 01/03/2020

\section{Abstract}

Introduction: Drug addiction is a recurrent and chronic mental illness that is associated with severe motivational disorders and loss of behavioral control, leading to personality disorder.

Aim: Present study aims to evaluation of Structural relations of brain-behavioral systems and Emotion regulation difficulties with craving of marijuana in students.

Method: This research was a correlation, study 200 individuals (102 male and 98 female) of School students of Tehran selected by clustering sampling and answered to following questionnaires: Carver and White's Behavioral Inhibition \& Activation Scale, Difficulties in emotion regulation scale and craving of marijuana in students' questionnaire. For data analysis, confirmatory factor analysis and structural equation modeling technique was used.

Results: The evaluation of hypothetical model with fit indexes demonstrated that the hypothetical model fits the measurement model (CFI=0.96, NFI=0.96, and RMSEA=0.045). Structural relations analysis also showed brain-behavioral systems indirectly affect through emotional dysregulation over craving of marijuana and also the results showed that the emotional dysregulation has a direct relation to craving of marijuana.

Conclusion: Thus, based on current research findings, it can be concluded that Emotion regulation difficulties has a mediating role in relationship Structural relations of brain-behavioral systems and craving of marijuana. Considering these dimensions and the effectiveness of the employed mechanisms can be useful in developing efficacious preventive and therapeutic interventions for craving of marijuana.

Keywords: Activation behavioral, Inhibition behavioral, Emotion regulation difficulties, Craving of marijuana, Structural model

How to cite this article : Memarpour Asiaban N, Imani S, Shokri O. Structural relations of brain-behavioral systems and emotion regulation difficulties with craving of marijuana in students. Shenakht Journal of Psychology and Psychiatry. 2020; 7 (1): 103-116 .URL: http://shenakht.muk.ac.ir/article-1-761-fa.pdf

Copyright (C) 2018 the Author (s). Published by Kurdistan University of Medical Sciences. This is an open access article distributed under the terms of the Creative Commons Attribution-Non Commercial License 4.0 (CCBY-NC), where it is permissible to download, share, remix, transform, and buildup the work provided it is properly cited. The work cannot be used commercially without permission from the journal. 


\title{
روابط ساختارى سيستمهاى مغزى - رفتارى و دشوارى در تنظيم هيجان با ولع مصرف مارىجوانا در دانش آموزان
}

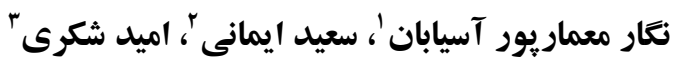

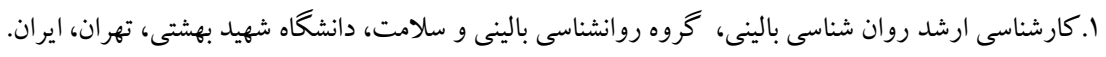

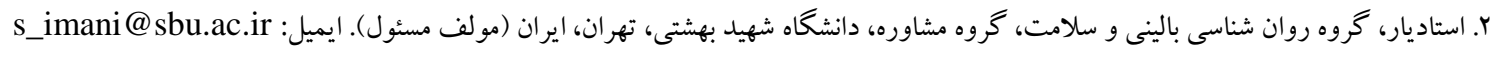 \\ r. استاديار، گروه روان شناسى تربيتى و تحولى، دانشكاه شهيد بهشتى، تهران، ايران.
}

تاريخ بذيذش مقاله: || ||

تاريخ دريافت مقاله:

جكيده

مقدمه: اعتياد به مواد مخدر، بيمارى روانى عودكننده و مزمنى است كه توأم با اختلالات انخيزشى شديد و از دست دادن تسلط رفتارى است و منجر به ويرانى شخصيت مى شود.

هدف: هدف ئزوهش حاضر، ارزيابى روابط ساختارى سيستمهاى مغزى - رفتارى و دشوارى در تنظيم هيجان با ولع مصرف مارى جوانا در دانش آموزان است.

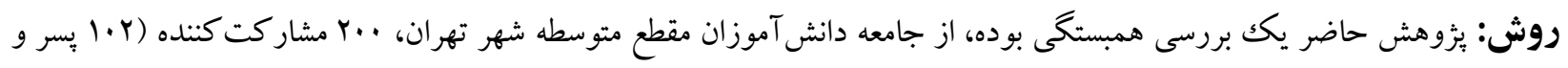
هو دختر) كه با روش نمونه گيرى خوشهاى انتخاب شدند به مقياس سيستم هاى بازدارى/ فعالسازى رفتارى كارور و وايت، مقياس

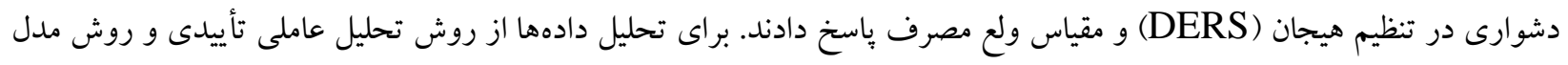
يابى معادلات ساختارى استفاده شد.

يافتهها: ارزيابى مدل فرضى ثُزوهش با استفاده از شاخصهاى برازندگى نشان داد كه مدل فرضى با مدل اندازهيرى، برازش دارد

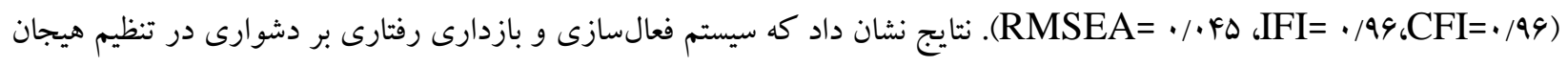

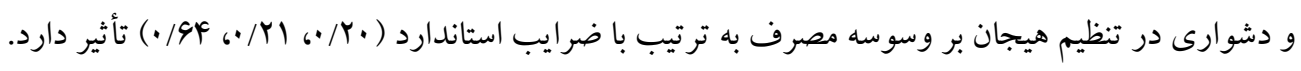

نتيجه كيرى: نتايج يزوهش نشان داد كه دشوارى در تنظيم هيجان در رابطه بين سيستمهاى مغزى رفتارى و وسوسه مصرف مارىجوانا

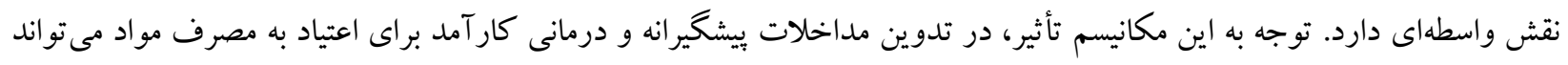
مؤثر باشد.

كليدوازهها: فعالسازى رفتارى، بازدارى رفتارى، دشوارى در تنظيم هيجان، ولع مصرف مارىجو انا، معادلات ساختارى 
مطالعات زيادى به اين نتيجه رسيدهاند كه وسوسه در

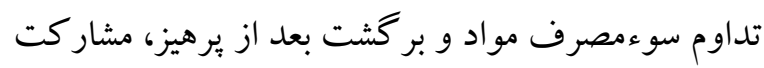

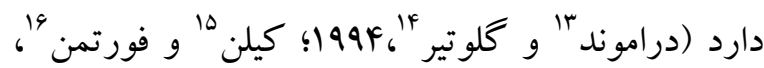

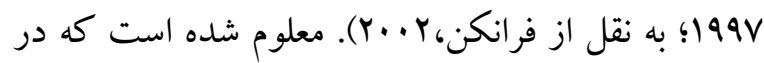
تجربه جنبهاى وسوسه تفاوتهاى فردى وجود دارد

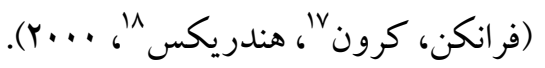
شواهد حاكى از اين است كه ويز كىهاى شخصيتى جزء ييشبينى كنندهاى مهم مصرف مواد و علائم روان شناختى از قبيل اضطراب و افسردگى هستند (مولائى، ابو القاسمى و آقابابايى، 19 1Y). در اين راستا، نتايج نشان

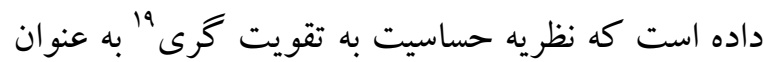
يكى از ويز گى هاى شخصيتى در گر ايش به مصرف مواد نقش برجسته ترى دارد. نظريه حساسيت به تقويت بهعنوان يكى از برجستهترين نظريههاى شخصيت مطرح شده

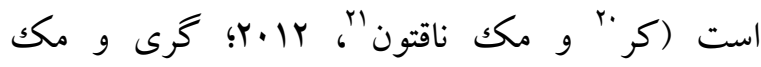
ناقتون، · ‥ مدل زيستشناختى شخصيت بوده كه مدعى است تفاوتهاى شخصيتى افراد از عملكرد سه سيستم مغزى عمده ناشى مىشود. اين سيستمها شامل سيستم فعالسازى

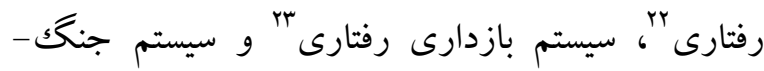

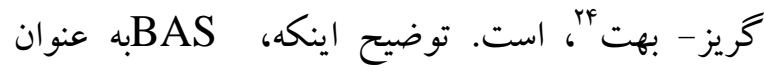
سيستم گرايشى زيربناى رفتار نزديكى است كه در باسخ به نشانهاى شرطى و غيرشرطى باداش فعال مىشود

11. Hendriks

12- Van den Brink

13 - Drummond

14 - Glautier

15 - Killen

16. Fortmann

17- Kroon

18 - Hendriks

${ }^{19}$ - Reinforcement Sensitivity Theory

${ }^{20}$ - Corr

21- Mc Naughton

22 - Behavioral approach system

23 - Behavioral Inhibition System

${ }^{24}$ - Fight-flight- freezing system

\section{مقدمه}

نوجوانى سنى حساس در ايجاد و گسترش رفتارهاى مقابله و ياسخ به نيازهاى محيطى است. اين دوره بهواسطه تغييرات سريع فيزيكى، روانشناختى، اجتماعى، فرهنكى و شناختى با انبوهى از مشكلات مغاير سلامت همراه است. بسيارى از عوامل تهديد كننده سلامت و رفتارهاى يرخطر توسط نوجوانان در همين سن به صورت بيشروندهاى شروع مىشود (اختيارى، YNV

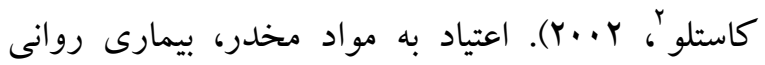

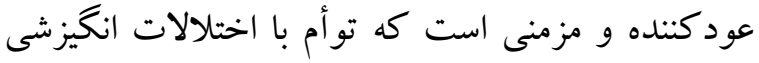
شديد و از دست دادن تسلط رفتارى است و منجر به ويرانى شخصيت مىشود. ميليونها انسان از اين اختلال رنج مىبرند كه اغلب با ديخر بيمارىهاى روانى بروز و ظهور يافته و هزينه هاى اقتصادى و اجتماعى گوناكونى را

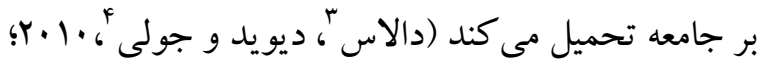

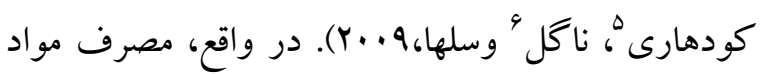
مخدر هزينههاى گزافى از طريق اثرات مخرب خود بر سلامت افراد و افزايش جرم و جنايت و مركتومير در جامعه تحميل كرده است و در نتيجه به يكك تهديد بزرك براى جوامع تبديل شده است (بيتر و آليسيا، . . (Y). يكى از ويز گحىهايى كه در اعتياد تجربه مىشوند،

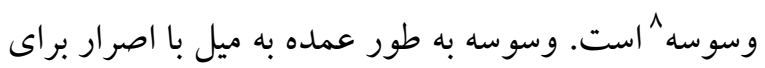
تجربه كردن اثر يك ماده روان كردان كه قبلاً تجربه شده

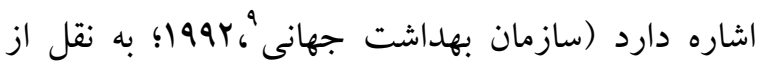

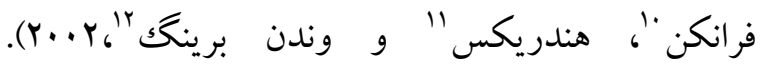

\footnotetext{
1- Armstrong

2 - Costello

${ }^{3}$ - Dallas

4- David \& Julie

5 - Choudhury

6 - Nagel \& Saleha

7- Peter \& Alicia

8 - Craving

9- Organizaton World Health

${ }^{10}$ - Franken
} 
تارنر "ا و ايواتا"، س...r؛ فاولز، 1991)؛ اما آنجه جاى سؤال و ترديد دارد اين است كه آيا اين سيستمها به عنوان صفات شخصيتى -زيستى تأثيرى مستقيم روى اين اختلالهاى سوءمصرف مواد دارد يا اينكه ساز و كار واسطهاى نيز وجود دارد؟ در اين ارتباط بيجتيبر، بك،

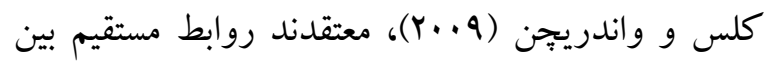
سيستمهاى مغزى - رفتارى گرى و اختلالات روانى از جمله اختلالهاى سوءمصرف مواد، فقط به طور نسبى مىتوانند تبيين گر اين رابطه بوده و در عوض مدلهاى تعاملى بيجيده مى تواند الكوى روابط بين اين متغيرها را

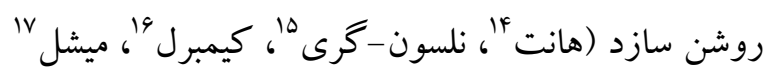

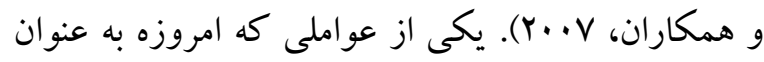
متغير واسطهاى توجه زيادى را از سوى يززوهشگران

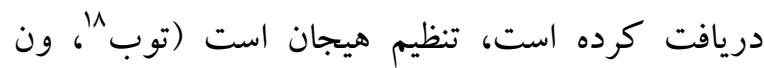

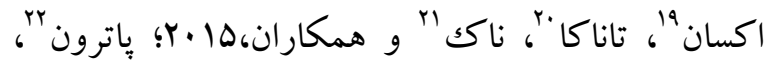

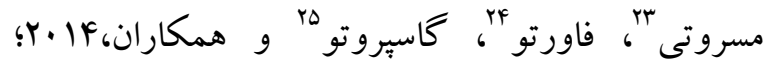

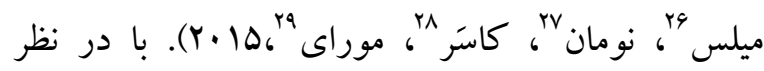
كرفتن اين موضوع در يثوهش حاضر به نقش ويزه دشوارى در تنظيم هيجان در اين الخو تأكيد شده است. برخى مفهوم سازى بيانگر اين هستند كه حساسيت BAS و BIS بر تنظيم و پِاسخكويى هيجانى تأثير

${ }^{11}$ - Johnson

12- Turner

13 - Iwata

${ }^{14}$ - Hundt

${ }^{15}$ - Nelson-Gray

${ }^{16}$ - Kimbrel

${ }^{17}$ - Mitchel

${ }^{18}$ - Taube

19- Van Exan

${ }^{20}$ - Tanaka

21- Wnuk

${ }^{22}$ - Patron

${ }^{23}$ - Messerotti

${ }^{24}$ - Favretto

${ }^{25}$ - Gasparotto

${ }^{26}$ - Mills

${ }^{27}$ - Newman

${ }^{28}$ - Cossar

${ }^{29}$ - Murray

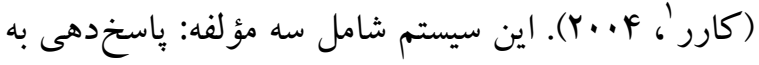

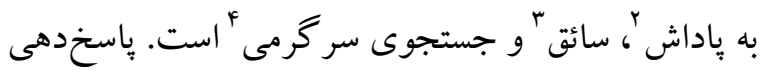
دهى به باداش مرتبط با پاسخ مثبت به رخداد و يا انتظار

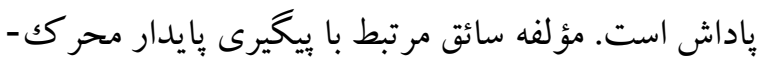
هاى لذتبخش و در نهايت مؤلفه جستجوى سرگرمى مرتبط با جستجوى هيجان و ميل به رويارويى با

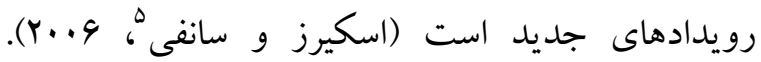
همجنين FFFS سيستم اجتنابى و دفاعى بوده كه اجتناب و فرار را در ياسخ به محرككهاى آزارنده شرطى و

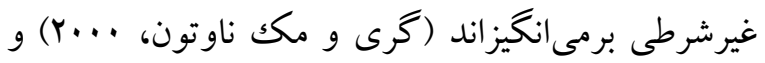
در نهايت BIS به عنوان سيستمى تلقى مىشود كه تعارض بين اهداف رقيب (براى مثال تعارض بين نزديكى

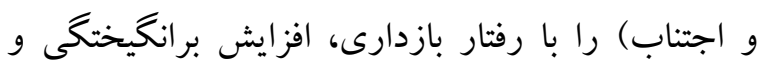
ارزيابى خطر حل مى كند (كرى و مكك ناوتون، .......

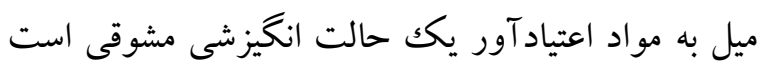

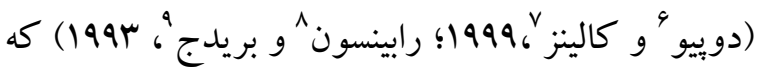
كه مى تواند با فعاليت سيستم فعالساز رفتارى تبيين شود. فعاليت سيستم فعالسازى رفتارى منجر مىشود كه شخص با اشتياق عملى را دنبال كند كه ممكن است نتيجه آن يّاداش باشد، بدون اين كه به عواقب منفى آن توجه

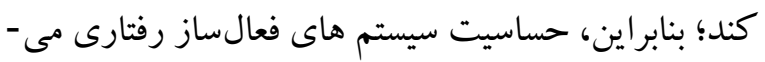
تو اند در افزايش مشكلات مصرف مواد نقش داشته باشد (بيجتيبر، بكك، كلس و واندريجن، 9. 9. (Y). شواهد

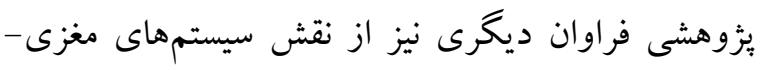

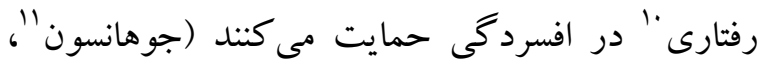

\footnotetext{
1- Corr

${ }^{2}$ - Reward Responsiveness

3 - Drive

4- Fun Seeking

5 - Scheres \& Sanfey

6- Depue

7. Collins

8 - Robinson

9 - Berridge

${ }^{10}$ - Brain-Behavioral Systems
} 
در جمع بندى مبانى نظرى و يزوهشى مطرح شده مى

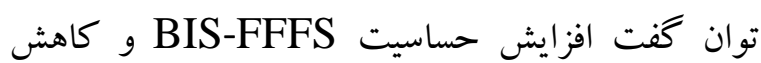
حساسيت BAS واكنش بذيرى هيجانى و دشوارى در تنظيم هيجان را در يى خواهد داشت (تول وهمكاران،

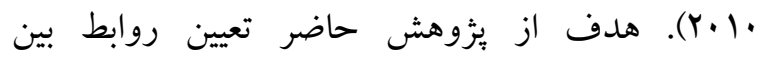
متغيرهاى فوق الذكر با استفاده از روش مدل يابى معادلات ساختارى (SEM) v است. در اين زيزوهش فرض بر اين است كه BIS-FFFS و BAS باداش به صورت مستقيم و به ترتيب رابطه مثبت و منفى با ERD و رابطه غيرمستقيمى با ولع مصرف مارىجوانا دارند. همجنين فرض شده است كه ERD رابطه مثبى با ولع مصرف دارد. در كنار ارائه اين الكوى فرضى وجود ساير روابط بين متغيرهاى بثروهش نيز بررسى شده است.

روش طرح بثزوهش حاضر با توجه به موضوع، اهداف و فرضيههاى مورد نظر از نوع توصيفى-همبستخى است. جامعه آمارى بززوهش را كليه دانش آموزان دوره متوسطه شهر تهران در سال تحصيلى حداقل حجم لازم براى يزوهش حاضر بر اساس شاخص ير كاربرد N بحرانى هولتر محاسبه شده است كه اين مقدار براى مدل فرضى ئزوهش و بر اساس متغيرهاى ينهان و مشهود برابر س/TV/T به دست آمد. هم جنين، با در نظر گرفتن حداقل حجم مورد نياز هنگامى كه متغيرهاى مشهود مدل (در مدل فرضى بثزوهش حاضر،10 متغير)

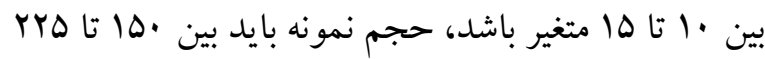
نفر باشد (كلاين، ·(Y). از اين رو، كل نمونه انتخاب

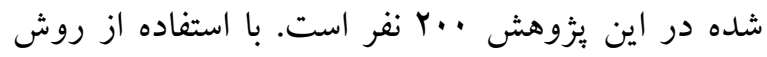

7- Structural equation modeling
مى گذارد (بجتيبر و همكاران، 9.+Y)؛ به عبارت ديخر اختلال در حساسيت اين سيستم ها بر بد تنظيمى هيجان مؤثر بوده و بر روشهايى كه افراد هيجانهاى خود را

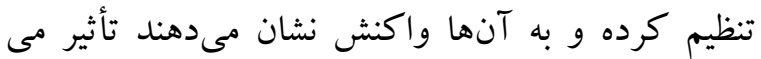
كذارد و مانع به كار گيرى راهبرهاى تنظيم هيجان ساز گارانه مىشود (ديو و اياكونو '، 1919). بثزوهش هايى كه رابطه ابعاد شخصيتى و دشوارى در تنظيم هيجان را مطالعه مى كنند، نشان از اين دارند كه حساسيت BIS به طور مثبت با ERD' رابطه دارد (ييكت، لوديس، بِاركيل

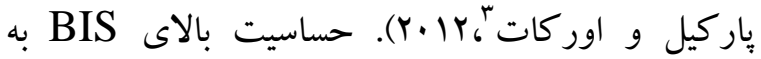
همراه ERDبه تلاش هاى ناساز گارانه براى تنظيم و ياسخدهى هيجانى و در نهايت افزايش خطر ابتلا به

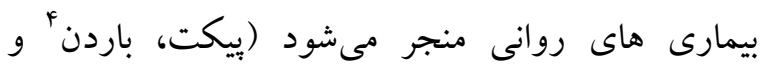

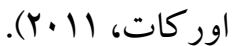
هرجند رابطه بين BAS و ERD به وضوح مشخص

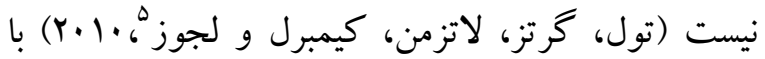
اين حال به نظر مىرسد BAS ياداش، رابطه منفى و سر گرمى، رابطه مثبت با ERD جنين رابطهاى بين BAS سائق و ERD يافت نشده است (تول و همكاران، · (Y. (Y). ئزوهش هاى اندكى اثر تعاملى BAS و ر بر بر بيامدهاى مشكل آفرين مطالعه

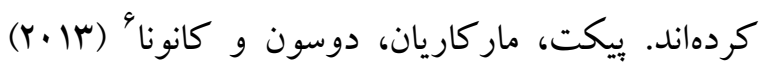
كزارش كردهاند كه حساسيت بايين BAS پراداش و در تعامل با هم باعث افزايش علائم اضطراب در هر دو گروه مبتلا به اختلالات خواب و گروه كنترل مى بـ

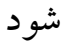

\footnotetext{
1- Depue \& Iacono

2- Emotion Regulation Difficulties

3 - Pickett, Lodis, Parkhill \& Orcutt

4 - Bardeen

5- Tull, Gratz, Latzman, Kimberl \& Lejuez

${ }^{6}$ - Pickett, Markarian, Deveson \& Kanona
} 
يرسشنامه سيتهم هاى بازد/رى/ فعال سازى رفتارى كارور و وايتْ : مقياس BAS/BIS (كارور و وايت، (199F)، يكك مقياس خود كزارش دهى FF سؤالى است. زيرمقياس BIS در اين برسشنامه شامل هفت گويه است كه حساسيت سيستم بازدارى رفتارى را در باسخ به نشانه هاى تهلديد اندازه مى گيرد. از طرفى زيرمقياس BAS نيز شامل سيزده گويه است كه حساسيت سيستم فعال سازى رفتارى را ارزيابى مى كند. BAS در اين بيرسشنامه خود شامل سه خرده مقياس: سائق (F سؤال)، ياسخدهى به ياداش (ه سؤال) و جستجوى سركرمى (F سؤال) است. جهار كويه اضافى به عنوان آيتم هاى بوششى در مقياس آورده شده كه نقشى در ارزيابى BAS/BIS ندارند. كويه ها روى يكك مقياس جهار درجه اى توسط آزمودنى رتبه بندى مى شود. ثبات درونى مقياس BIS و BAS به ترتيب برابر BA • • و • • است، آلفاى كرونباخ براى مقياس بازدارى رفتارى VV/· و براى مقياس فعال سازى رفتارى V9/. كزارش شده است؛ (كارور و وايت،

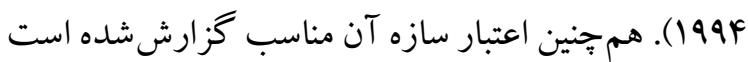

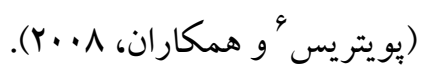

مقياس دشوارى در تنظيم هيجان (DERS) يكك ابزار سنجش وب آيتمى است كه براى ارزيابى دشوارى در تنظيم هيجان تدوين شده است. تحليل عاملى وجود 9 عامل عدم بذيرش بِاسخهاى هيجانى (9 سؤال)، دشوارى در انجام رفتار هدفمند (ه سؤال)، دشوارى در كنترل تكانه (4 سؤال)، فقدان آكاهى هيجانى (4 سؤال)، دسترسى محدود به راهبردهاى تنظيم هيجانى ( م سؤال) و عدم وضوح هيجانى (ه سؤال) رادر اين مقياس نشان داده است. نتايج حاكى از آن است كه اين مقياس از همسانى

5- Carver \& White

${ }^{6}$ - Poythress

7- Difficulties in Emotion Regulation Scale
نمونه گيرى خوشهاى ابتدا از بين فهرست مدارس موجود در نواحى آموزش و برورش شهر تهران · ا دبيرستان (هركئ دبيرستان يُر انه و ه دبيرستان دخترانه) انتخاب شد. يس

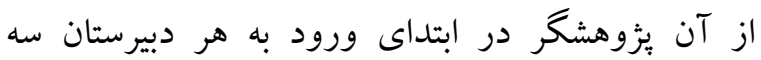
كلاس به صورت تصادفى ساده (يكك كلاس از هر بايه تحصيلى) براى اجراى برسشنامها انتخاب كرد و همه دانش آموزان كلاس، برسشنامه ها را به صورت داوطلبانه

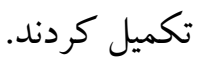

در مطالعه حاضر به كارگيرى روش مدل يابى معادلات ساختارى جهت ارزيابى برازش مدل فرضى با بهره گيرى از بسته نرمافزارى LISREL صورت يذيرفت. در مدل يابى معادلات ساختارى براى اندازهگيرى هر متغير

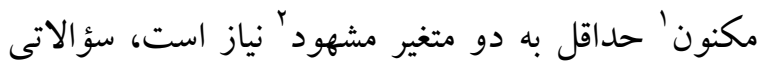
كه در هر مقياس بيشترين بار عاملى را داشتند به عنوان نشانخر (متغير مشهود) هاى آن متغير در نظر كرفته شدند. به كارگيرى روش SEM مستلزم بررسى اوليه بيش

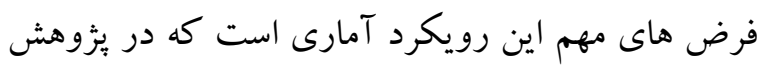
حاضر توجه ويزه اى به اين بخش صورت كرفته است. تحليل داده ها با استفاده از رويكرد دو مرحله اي بـ (آندرسون و گربينگ اول تحليل عاملى تأييدى (CFA+) براى ارزيابى برازش

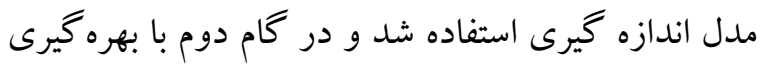
از روش مدل يابى معادلات ساختارى، الخوى ساختارى

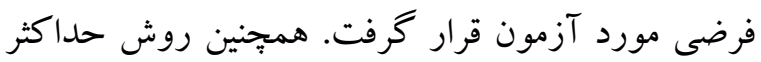
درست نمايى براى تخمين بارمترها به كار برده شد.

1. Latent variable

2 - Observed variable

3 - Anderson \& Gerbing

${ }^{4}$ - Confirmatory Factor Analysis 


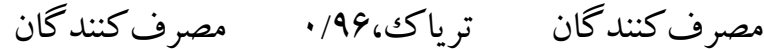

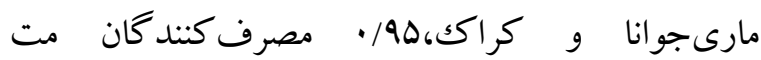

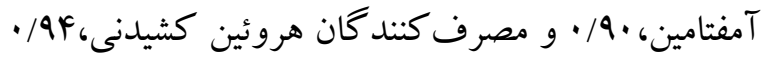

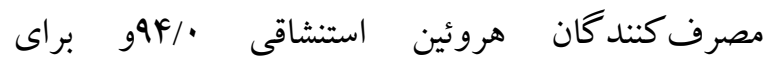

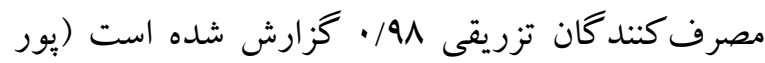

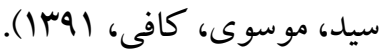

يافتهها مدل يابى معادلات ساختارى روشى مبتنى بر ماتريس واريانس - كواريانس " است. از اين رو داده هاى از

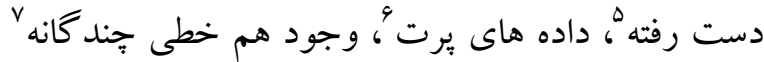

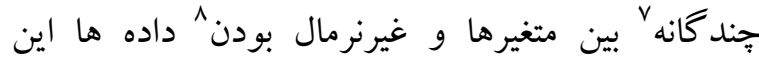
ماتريس را تحت تأثير قرار داده و به دنبال آن نتايج سودار

$$
\text { و غيرواقعى در اختيار مى كذارد. }
$$

اكثر شاخصهاى آمارى كه در SEM به كار مىروني بر فرض نرمال بودن استوار هستند. در اين رويكرد بايد هم نرمال بودن تكك متغيرى" و نيز نرمال بودن جِند

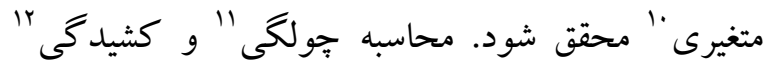
هريك از متغيرهاى مشهود، روشى معمول براى ارزيابى نرمال بودن تكك متغيرى است. همان كونه كه در جدول

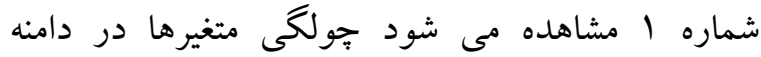

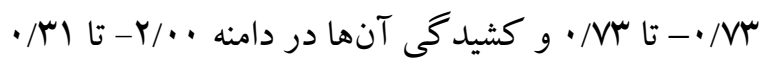
قرار دارد. جو و بنتلر (1990) نقطه برش سـ را براى مقدار جولكى مناسب مىدانند. اكرجه توافق اندكى درباره نقطه برش كشيدگى وجود دارد ولى به طور كلى

4- Variance-Covariance Matrix

5- Missing Data

6 - Outliers

7- Multicollinearity

8 - Non-normality

${ }^{9}$ - Univariate normality

${ }^{10}$ - Multivariate normality

11 - Skewness

${ }^{12}$ - Kurtosis
درونى بالايى برخوردار است. هر شش مقياس DERS ،

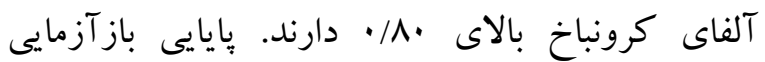
مقياس دشوارى در تنظيم هيجان براى مقياس عدم بذيرش هيجان هاى منفى سم//•، براى دشوارى در انجام رفتارهاى هدفمند هA/·، براى دشوارى در مهار رفتارهاى تكانشى 9^/•، براى دستيابى محدود به راهبردهاى اثربخش تنظيم هيجان VA/، براى فقدان آكاهى هيجانى

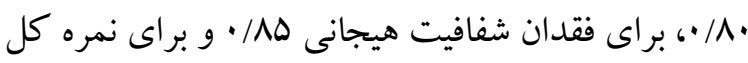
مقياس AVV/• است (ويت و وير، سAM 1). روايى مقياس در

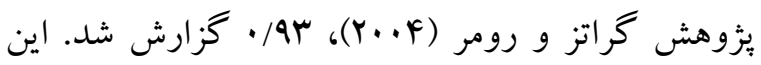

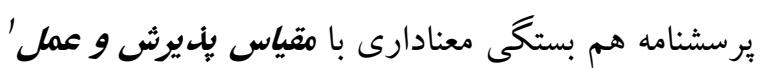

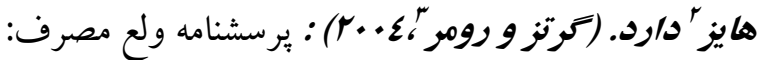
مصرف: اين برسشنامه شامل flf فرانكن، هندريكس و واندن برينكك (Y......)، ساخته شده است. اين وبرسشنامه از مقياس ميل به الكل مشتق شده است كه براى وابستخان به هروئين مورداستفاده قرار مى كيرد؛ اما به علت توانايى سنجش كلى مواد، بعدها در سنجش ولع ساير مواد به كار رفت. اين ابزار ولع كنونى را بررسى كرده و داراى سه خرده مقياس ميل به مصرف مواد، تقويت منفى و كنترل ادراكشده بر مصرف مواد است. اين برسشنامه بر اساس مقياس Vتايى ليكرت (كاملاً مخالف تا كاملاً موافق) است. نمره گذارى از يكك تا هفت

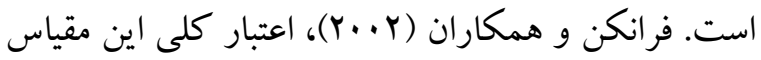
را به روش آلفاى كرونباخ هی/· • و براى خرده مقياسهاى ميل به مصرف و قصد مصرف مواد، تقويت منفى و كنترل ادراككشده بر مصرف مواد به ترتيب •/AV،/A • و

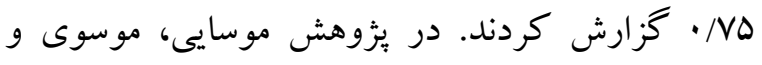
كافى (الqسا)، مقدار آلفاى كرونباخ كلى براى

\footnotetext{
1- Acceptance and Action Questionnaire

2. Hyse

3. Gratz \& Roemer
} 
خطى جند گانه بين آنهاست. ضرايب همبستگى در دامنه

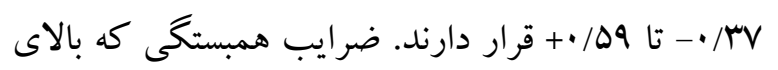
ه/ • باشند در تخمين صحيح مدل مشكل ايجاد مى كنند

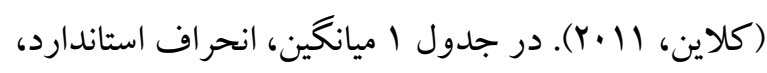
جولكى، كشيد يُزوهش نشان داده شده است. همه بارهاى عاملى از لحاظ

$$
\text { آمارى معنى دار است. }
$$

مقادير بيش از · إ براى اين شاخص مسئله آفرين بوده و مقادير بيش از •Y士 نتايج به دست آمده را نامعتبر مىسازد

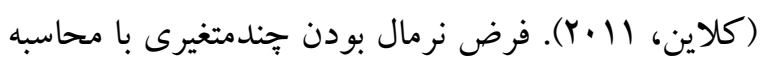
شاخص كشيد گى جندمتغيرى نسبى بررسى شد كه مقدار

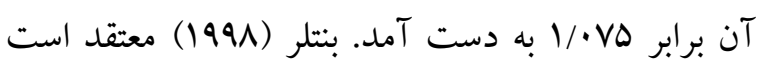
در صورتى كه ارزش اين شاخص بيشتر از ب نباشد نرمال بودن جند متغيرى محقق شده است. بررسى ماتريس همبستكى بين متغيرهاى مشهود حاكى از عدم وجود هم مدئ

\begin{tabular}{|c|c|c|c|c|c|}
\hline بار عاملى (ضرايب & كشيدكى & جولكى & استاندارد انحراف & ميانكين & متغيرها \\
\hline$\cdot / A$ & $-\cdot / r$ & $\cdot / \Delta \Delta$ & $1 / .9$ & $1 / m q$ & BISI \\
\hline . / & I & $-\cdot / 49$ & $\cdot / M$ & $r / r q$ & BISr \\
\hline .199 &.$- / .0$ & $\cdot / \Delta r$ & $1 / \cdot r$ & $1 / \Delta V$ & BISTr \\
\hline.$/ I V$ &.$/ F T$ & $-1 / \cdot 4$ & $r / .0$ & $11 / .9$ & ياداش \\
\hline$\cdot / 9$. & $\cdot / 4$ & $1 / 19$ & r/vA & $V / 9 \mathrm{~V}$ & سائق \\
\hline.$/ 94$ & $-\cdot / \cdot v$ &.$/ 99$ & $r / A V$ & V/a9 & سركرمى \\
\hline$\cdot / N Y$ & .194 & $\cdot / \wedge \Delta$ & r/TO & $r / r q$ & عدم يذيرش \\
\hline$\cdot / v$ & .194 & $\cdot / A F$ & $r / r)$ & $\Delta / \Delta F$ & دشوارى \\
\hline$\cdot / \wedge \Delta$ & $r / 19$ & $1 / T V$ & $r / 19$ & $F / F A$ & تكانشى \\
\hline$\cdot / V^{F}$ &.$/ 91$ & $\cdot / \mathrm{VV}$ & $r / l$ & $r / 99$ & راهبرد \\
\hline$\cdot / A F$ & 1/AD & $1 / \pi 1$ & $\Delta / \cdot V$ & $V / 9$. & فقدان آكاهى \\
\hline / Ar & $1 / 19$ & $1 / M r$ & $\Delta / I V$ & $\mathrm{~V} / \mathrm{V}$. & وضوح \\
\hline / Nr & $9 / 79$ & r/qY & $r / 11$ & $9 / 41$ & ميل \\
\hline$\cdot / \mathrm{Al}$ & $11 / 49$ & r/Ar & $r / . r$ & $11 / 49$ & تقويت \\
\hline - /AF & $11 / 19$ & r/A9 & $F / . r$ & $1 \cdot / N V$ & كنترل \\
\hline
\end{tabular}

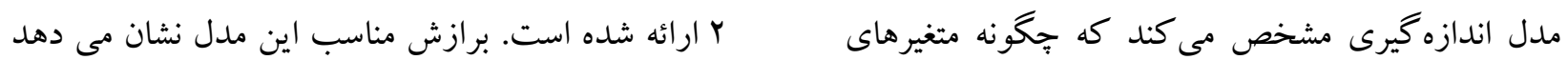
مشهود به متغيرهاى مكنون مربوط مىشود. ارزيابى اين كه متغيرهاى مشهود كفايت لازم براى عملياتى كردن مدل با استفاده از روش تحليل عاملى تأييدى انجام مىشود. شاخصهاى برازش مدل اندازه گيرى در جدول

جدول r شاخص هاى برازندكى الكوى اندازه كيرى متغيرهاى بروهش

$\begin{array}{lllllll}\text { IFI NFI } & \text { CFI } & \text { GFI } & \text { SRMR } & \text { RMSEA } & \text { Chi-Square/df } & \text { Chi-Square }\end{array}$




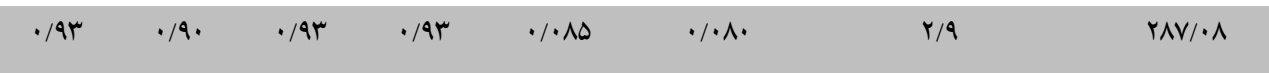

اسكوئر به درجه آزادى، SRMR و RMSEA است. شاخص هاى افزايشى يا مقايسهاى برازش مدل

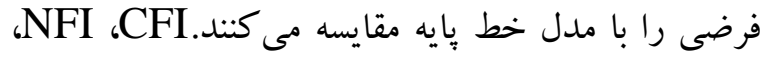
TLI و Tز اين شاخصها هستند. شاخصهاى برازندگى مدل فرضى در جدول ب آورده شده است.
شاخصهاى برازش مطلق و افزايشى براى تعيين برازش مدل اندازه گيرى و مدل ساختارى فرضى استفاده شد. شاخصهاى مطلق جكونغي برازش مدل را بدون مقايسه با مدل خط بايه كه در واقع مدل استقلال است تعيين مى كند. اين شاخصها شامل كاى اسكوئر، نسبت كاى

\begin{tabular}{|c|c|c|c|c|c|c|c|c|}
\hline TLI & IFI & NFI & CFI & GFI & SRMR & RMSEA & Chi-Square/df & Chi-Square \\
\hline$\cdot / 90$ & . /99 &.$/ 9$. & . /99 & . $/ 94$ & .1 .91 &.$/ . F \Delta$ & $1 / 4$. & 1.r/Tq \\
\hline
\end{tabular}

از اصلىترين شاخصهاى برازش مدل است كه براى آن

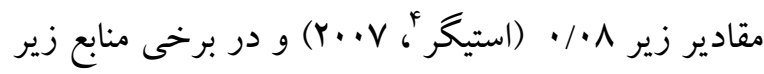
4.9.

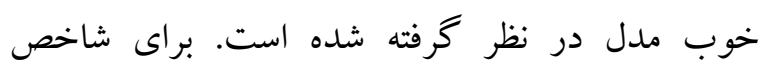

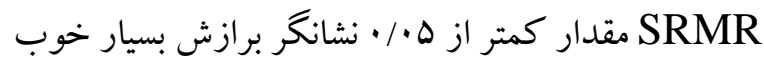

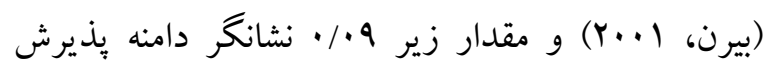

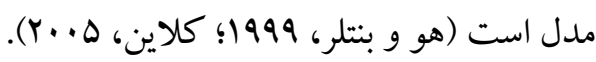
براى شاخصهاى IFI و TLI CCFI NFI مقادير بالاى 9/ • نشان دهنده هذيرش مدل و مقادير بالاى هـ/ • نشان از برازش خوب مدل دارد (هو و بنتلر، $1999 ؛$

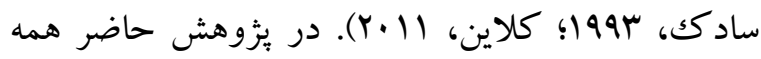
شاخص ها نشان دهنده برازش خوب مدل فرضى است. شكل ا مدل ضرايب استاندارد شده را نشان مى دهد.

${ }^{4}$ - Steiger
شاخص كاى اسكوئر براى ارزيابى برازش كلى مدل به كار رفت ولى اين شاخص به شدت تحت تأثير اندازه

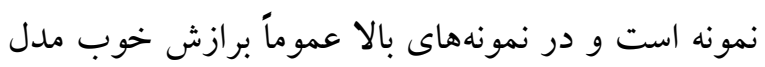

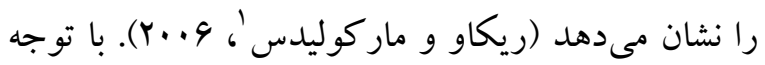

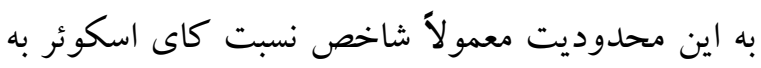
درجه آزادى بنيز گزارش مى شود كه تأثير مقدار نمونه را در شاخص كاى اسكوئر به حداقل مى رساند. سخت كيرترين معيار براى اين شاخص را تيّاجنيك و و

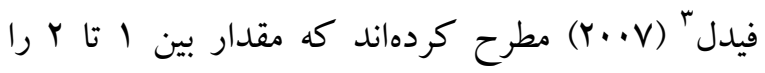

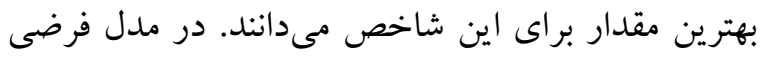

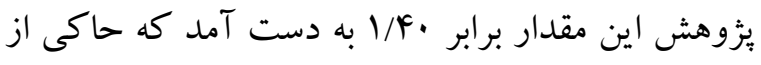
برازش مناسب مدل است. شاخصى است جايكزين كاى اسكوئر كه به حجم

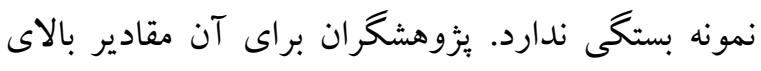

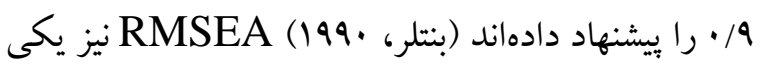

\footnotetext{
1- Raykov \& Marcoulides

2 - Chi-square ratio to free degree

3. Tabachnik \& Fidell
} 


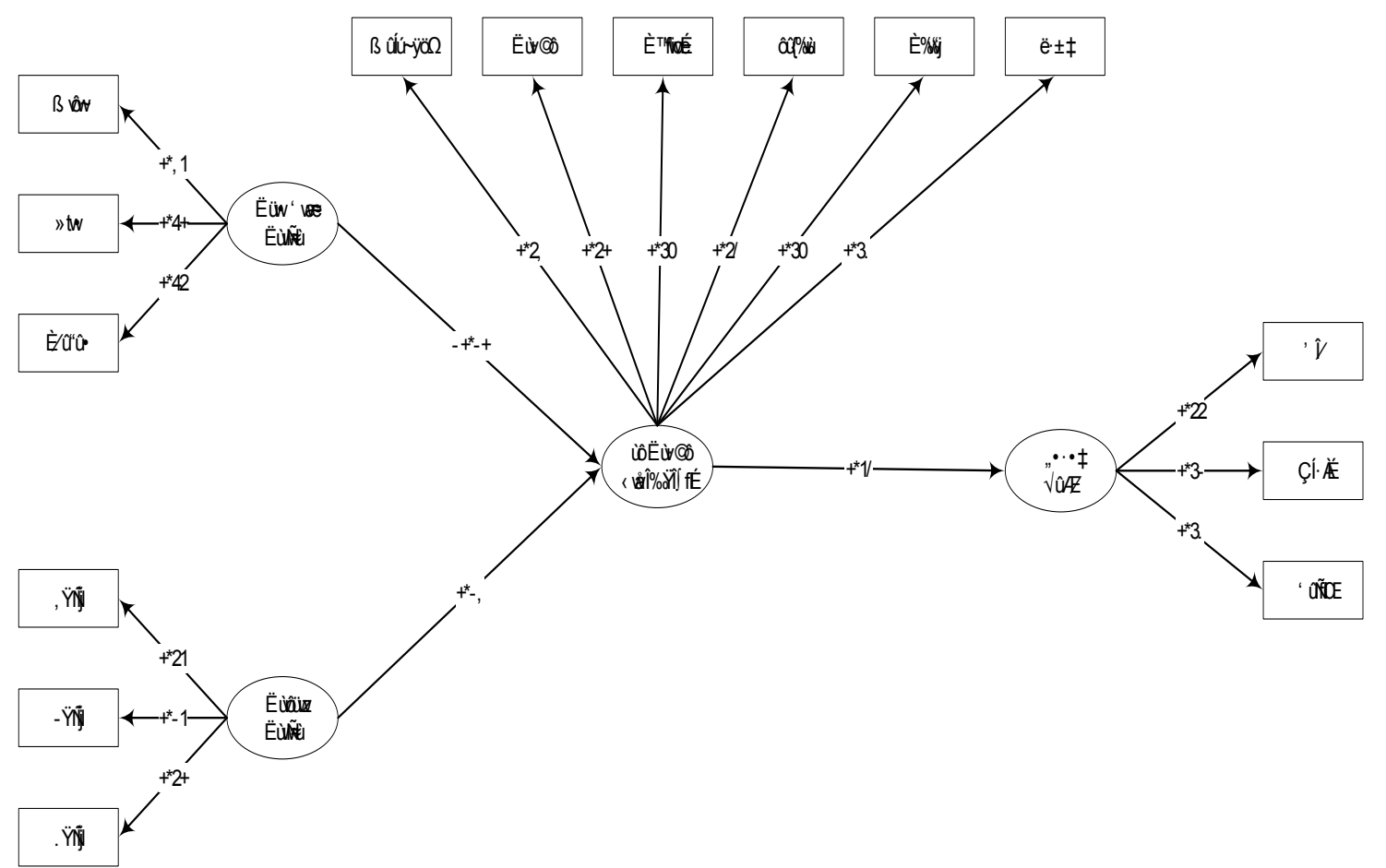

شكل 1 مدل ضرايب استاندارد شده

در شكل ا نشان مىدهد BIS ( BI/ در مطالعه حاضر با استفاده از يكك مدل ساختارى فرضى، BAS-REW

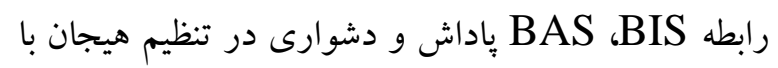
معنىدارى بر روى دشوارى در تنظيم هيجان دارند كه ولع مصرف مارى جوانا مورد آزمون قرار گرفت. همان

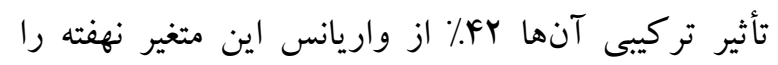
كونه كه فرض شده بود يافته ها از مدلى حمايت كردند تبيين مى كند. دشوارى در تنظيم هيجان نيز اثر مستقيم

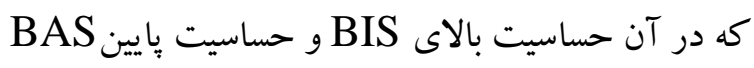

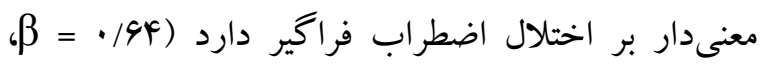
ياداش بهواسطه دشوارى در تنظيم هيجان باعث افزايش

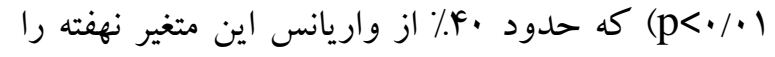
ولع مصرف مارىجوانا در دانش آموزان مىشود. يافتههاى اين بيزوهش مطابق با يافتهاى تول و همكاران تبيين مى كند. در مدل فرضى براى دو متغير سيستم فعالسازى رفتارى و سيستم بازدارى رفتارى اثرات

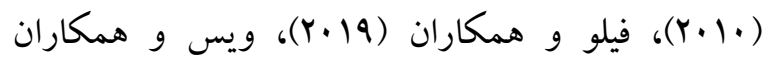
غيرمستقيم بر روى اختلال اضطراب فراكير در نظر گرفته (Y. M) (Y) و و حساسيت پيايين BAS شده بود. نتايج به دست آمده نشان مى دهد كه سيستم دشوارى در تنظيم هيجان را تجربه مى كنند. رابطه BIS با ليان دشوارى در تنظيم هيجان مىتواند ناشى از اين باشد كه

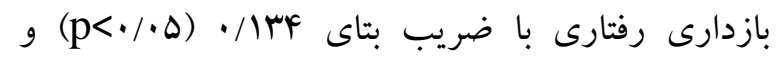
سيستم فعال سازى رفتارى- ياداش با ضريب بتاى بـان

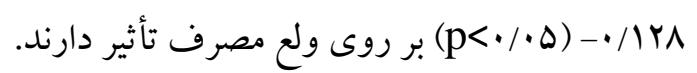


در تنظيم هيجان منجر به ييامدهاى منفى مى شود. درنتيجه

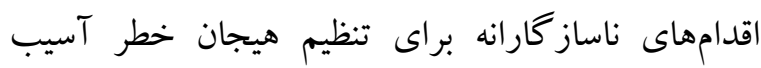
شناسى روانى را افزايش مىدهد (بيكت و همكاران،

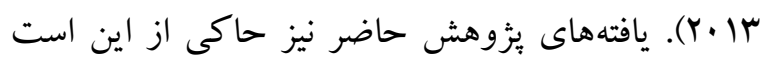
كه حساسيت بالاى سيستم بازدارى رفتارى اثر مثبتى در

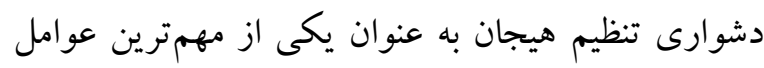

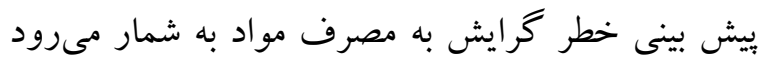

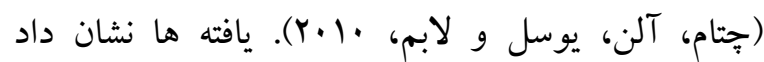
دشوارى در تنظيم هيجان اثر مثبتى بر وسوسه دارد. به نظر مىرسد افراد با حساسيت بالاى سيستم بازدارى رفتارى اضطرابشان بالا مىرود و براى تنظيم هيجان خود به دليل نداشتن مهارت تنظيم هيجان، به سمت مصرف مواد سوق بيدا مى كنند و مصرف مواد را به عنوان راهبردى براى رهايى از اين حالت ناخوشايندشان به كار مى برند.

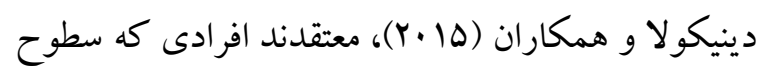
بالايى از نقايص تنظيم هيجان را بروز مىدهند، بيش از

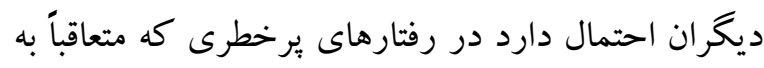

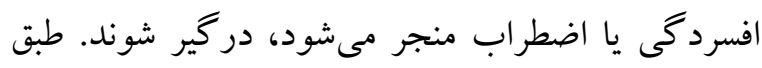

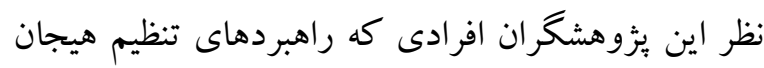
ضعيف را فراكر فنهاند ممكن است بيش از ديخران مستعد استفاده از رفتارهاى برخطر به عنوان ابزارى براى تسكين

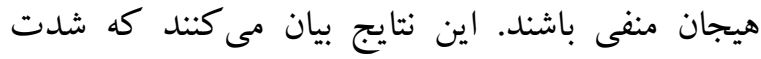

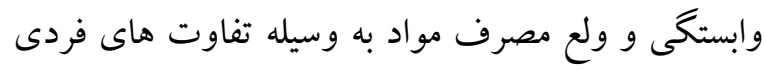
در نظم جويى شناختى هيجان ويش بينى مى شوند. در

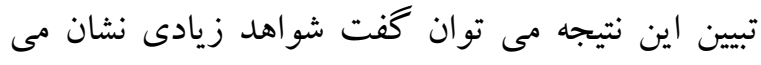
دهند كه فرايندهاى بد تنظيمى هيجانى عاطفى پايه و اساس جنبه هاى كليدى رفتار مصرف مواد از جمله

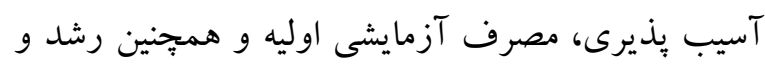

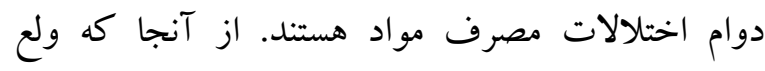

به عنوان يك صفت زيستى شخصيت BIS واكنشيذيرى هيجانى منفى را در افراد افزايش مىدهد

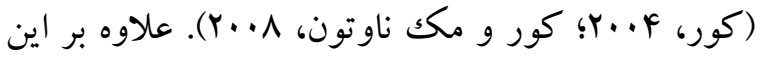
حساسيت بالاى BIS باعث مىشود افراد راهبردهاى

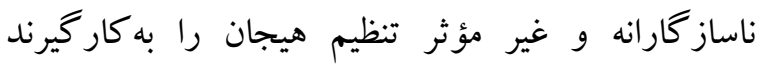

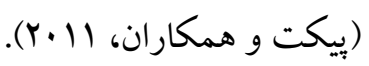
هم جنين رابطه منفى بين BAS پاداش و دشوارى در

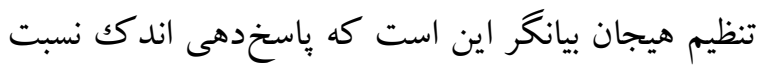

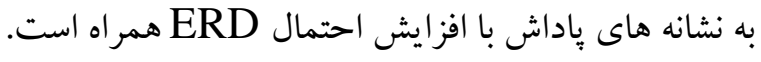

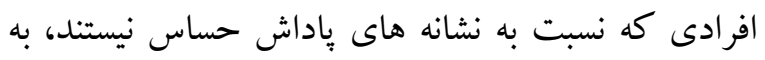
سختى مى تواند موقعيت هايى كه ظرفيت و بِتانسيل ارائه باداش را دارند تشخيص داده و يا بيش بينى كنئد

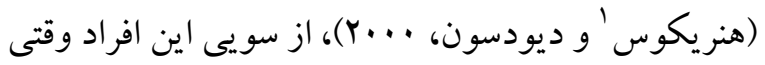
تجارب منفى را تجربه مى كند به سختى مىتوانند به حالت عادى خود بركردند (تو كيد و فريدريكسون،

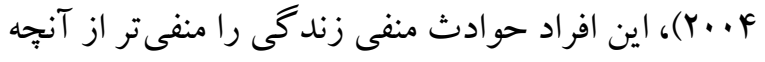
كه هست ارزيابى يا تجربه مى كند جرا كه انتظار و ييش بينى باداش آنها بإيين است و به دنبال تجاربى كه نتيجه

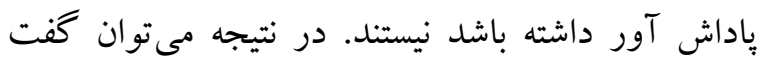

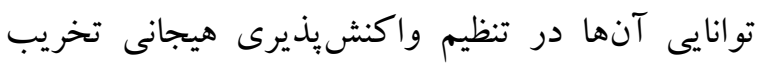

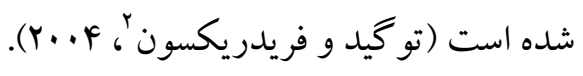
علاوه بر اين، ارتباط قوى بين دشوارى در تنظيم هيجان و مصرف مو اد داشت؛ (هيجان بذيرى بالا) كه مؤلفه كليدى

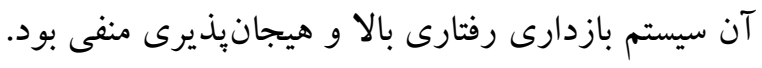
بنابر اين به نظر مىرسد عاملى كه بين ارتباط مثبت سيستم بازدارى رفتارى و اعتياد نقش بازى مى كند عدم تنظيم هيجان است. در اين راستا شواهد بيانكر اين است كه حساسيت بالاى سيستم بازدارى رفتارى همراه با دشوارى

\footnotetext{
1- Henriques

2- Tugade \&Fredrickson
} 
هرجند بسيارى از يُزوهشخران از مفهومسازى اختلالات روانى در ساختارى ابعادى حمايت مىكنند و بر اين باورند كه نتايج به دست آمده از محيطهاى بالينى و غير بالينى تا حد زيادى مطابق هم هستند. بايد در تعميم نتايج اين مطالعه به محيط بالينى احتياط كرد. محدوديت ديخر باليخ اينكه ماهيت مقطعى مطالعه حاضر، مانع استنتاجهاى علّى و شناخت دقيق ماهيت واقعى روابط بين متغيرهاى يزوهش مىشود. احتمال زيادى وجود دارد كه ترتيب زمانى شكل گيرى متغيرها بر اساس مدل فرضى ارائهشده باشد؛ با وجود اين، قطعاً نمىتوان بر بايه اين مطالعه حالتهاى جايگزين ديخر را رد كرد. سرانجام اينكه در اين مطالعه براى ارزيابى هر كدام از متغيرها تنها از يكك

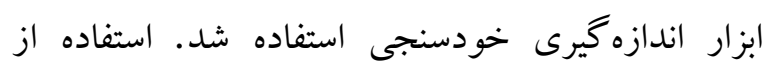
روشهاى اندازهيرى متنوع مى تواند به مفهومسازى بهتر متغير كمكك كند. با توجه به محدوديتهاى بثوهش، ييشنهاد مىشود مطالعه حاضر روى جمعيت بالينى يا جمعيتهاى غير دانشجويى نيز انجام شود تا توان تعميم دهى يافتهاى آن افزايش يابد. هم جنين به منظور استنتاج روابط على و شفاف كردن توالى زمانى بين متغيرهاى يزّوهش، انجام مطالعات طولى بيشنهاد مى شود.

\section{سياسگز ارى}

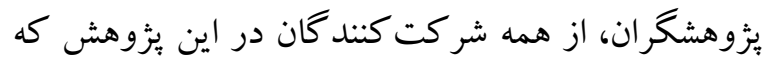
نهايت همكارى رادر اجراى اين بثزوهش داشتهاند، تشكر درّك

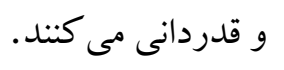

\section{References}

Anderson JC, Gerbing DW. (1988). Structural equation modeling in practice: A review and recommended two-step approach. Psychological Bulletin, 103, 411-423.
مصرف يا هوس كردن مواد به معناى داشتن انتظارات مثبت از اثرات مواد است؛ استفاده از راهبردهاى ملالت خويشتن، نشخوار گرى و فاجعه سازى در افرادى كه در مرحله تركك مواد هستند باعث مىشود كه فرد نخرش

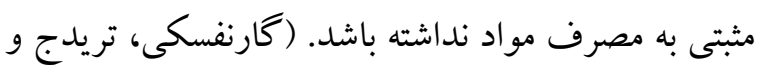

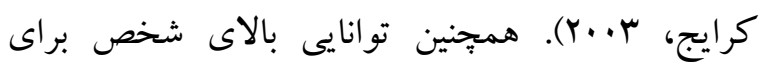
كنترل هيجان نيز مىتواند منجر به كنترل فكر فرد نسبت به مواد شده و ولع مصرف را كاهش دهد. هميجنين در تبيين نتايج حاصل از اين بززوهش مى توان كفت يكى از

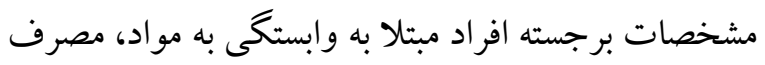

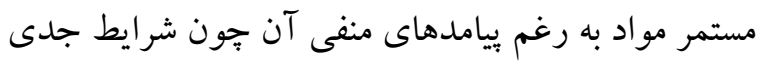
يزشكى، مشكلات قانونى، از دست دادن شغل، دوستان و

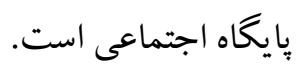

\section{نتيجه كيرى}

به طور خلاصه نتايج يزوهش نشان داد كه سيستم هاى مغزى رفتارى، دشوارى در تنظيم هيجان، علائم روان شناختى از بيش بينى كنندهاى ولع مصرف مارى جوانا

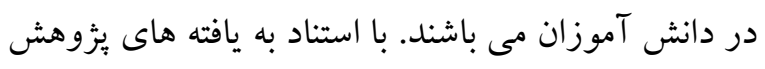
حاضر مىتوان به مديران مدارس و والدين و متخصصان مرتبط بيشنهاد كرد كه به علائم روان شناختى از قبيل اضطراب و استرس و تنظيم هيجان دانشآموزان توجه بيشترى كرده و برنامه هايى جهت بيشخيرى از سوءمصرف مواد داشته باشند. با اين كه يافتها از مدل

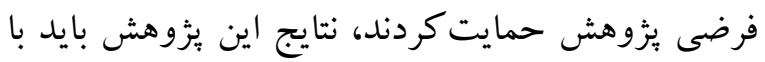
در نظر كرفتن محدوديتهاى آن تفسير شود. ابتدا اينكه مطالعه حاضر روى دانش آموزان كه جمعيت نسبتاً همكنى هستند، انجام شده است؛ بنابراين، در تعميم نتايج به

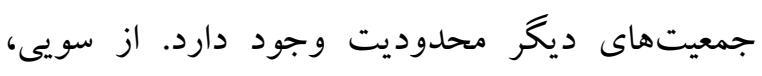


Armstrong TD, Costello EJ. (2002). Community studieson adolescent substance use, abuse, or dependenceand psychiatric comorbidity. J CounsClin Psycho; 70(6): 1224.

Bentler P, Kurtosis, Residuals, Fit Indices. (1998). Message posted to SEMNET discussion list. Available from http://bamaua.edu/cgibin/wa?A2=ind9803\&L=semnet\&T = $0 \& \mathrm{O}=\mathrm{D} \& \mathrm{P}=20612$.

Bentler PM, (1990). Comparative fit indexes in structural models. Psychological Bulletin, 107, 238-246.

Bijttebier P, Beck I, Claes L, Vandereycken W. (2009). Gray's reinforcement sensitivity theory as a framework for research on personalitypsychopathology associations. Clinical Psychology Review, 29,421-430.

Byme BM. (2001). Structural equation modeling with AMOS. Mahwah, NJ: Lawrence Erlbaum Associates.

Carver CS, White TL. (1994). Behavioral inhibition, behavioral activation, and affective responses to impending reward and punishment: The BIS/BAS scales. Joumal of Personality and Social Psychology, 67, 319-333.

Chou CP, Bentler PM. (1995). Estimates and tests in structural equation modeling. In R. H. Hoyle, Structural equation modeling: Concepts, issues and applications. Califomia: Sage.

Choudhury S, Nagel k, Saleha J. (2009). Critical neuroscience: Linking science and society through critical practice. Journal of Biosocieties, 34, 61-77.

Corr PJ, McNaughton N. (2008). The Reinforcement Sensitivity Theory of Personality. Cambridge University Press, New York, pp.155-187.

Corr PJ. (2004). Reinforcement sensitivity theory and personality. Neuroscience and Bio behavioral Reviews, 28, 317-332.

Dallas TX, David W, Julie K. (2010). Staley behavioral neuroscience of drug addiction. Joumal of Biosocieties, 6, 22-39.

Depue RA, Iacono WG. (1989). Neurobehavioral aspects of affective disorders. Annual Review of Psychology, 40, 457-492.
Depue RA, Iacono WG. (1989). Neurobehavioral aspects of affective disorders. Annual Review of Psychology, 40, 457-492.

Di Nicola M, Tedeschi D, De Risio L, Pettomuso M, Martinotti G, Ruggeri F, Janiri L. (2015). “Cooccurrence of alcohol use disorder and behavioral addictions: relevance of impulsivity and craving'. Drug and Alcohol Dependence. $148,118-125$.

Fillo J, Kamper-DeMarco KE, Brown, WC, Stasiewicz PR, Bradizza CM. (2019). Emotion regulation difficulties and social control correlates of smoking among pregnant women trying to quit. Addictive behaviors, 89, 104-112.

Fowles DC. (2001). Biological variables in psychopathology: a psychobiological perspective. In Adams, H. E. \&. Sutker, P. B. Comprehensive Handbook of psychopathology. New York: Kluwer Academic/Plenum, p. 85-141.

Franken IH, Kroon LY, Wiers RW, Jansen A. (2000). Selective cognitive processing of drug cues in heroindependence. Psychopharmacol, 14(3), 395-401.

Franken IHA, Hendriks VM, Van den Brink W. (2006). Initial Validation of two opiate craving questionnaires The Obsessive Compulsive Drug Use Scale and the Desire for Drug Questionnaire. Addictive Behaviors, 27, 675685.

Garnefski N, Teerds J, Kraaij V, Legerstee J, van den Kommer T. (2004). "Cognitive emotion regulation strategies and depressive symptoms: differences between males and females". Personality and Individual Differences. 36(2), 267-276.

Gratz KL, Roemer L. (2004). Multidimensional assessment of emotion regulation and dysregulation: development, factor structure, and initial validation of difficulties in emotion regulation scale. Journal of Psychopathology and Behavioral Assessment, 26, 41-54.

Gray JA, McNaughton N. (2000). The neuropsychology of anxiety: An enquiry into the functions of the septohippocampal system. New York: Oxford University Press. 
Hu L, BentlerP. (1999). Cutoff criteria for fit indexes in covariance structure analysis: conventional criteria versus new altematives. Structural Equation Modeling; 6(1): 1-55

Hundt NE, Nelson-Gray R O, Kimbrel NA, Mitchell JT, Kwapil TR. (2007) .The interaction of reinforcement sensitivity and life events in the prediction of anhedonic depression and mixed anxiety-depression symptoms. Personality and Individual Differences, 43, 1001-1012.

Johnson SL, Turner RJ, Iwata N. (2003). BIS/BAS levels and psychiatric disorder. An epidemiological study. Joumal of Psychopathology and Behavioral Assessment, 25, 25-36.

Kline RB. (2011). Principles and practice of structural equation modeling .3nd Ed. New York: Guilford.

McNaughton N, Corr PJ. (2008). The neuropsychology of fear and anxiety: A foundation for Reinforcement Sensitivity Theory. In P. J. Corr (Ed.), the reinforcement sensitivity theory of personality (pp. 44-94). New York, NY: Cambridge University Press.

Mills P, Newman EF, Cossar J, Murray G. (2015). "Emotional maltreatment and disordered eating in adolescents: Testing the mediating role of emotion regulation". Child Abuse \& Neglec. 39, 156-166.

Mowlaie M, Abolghasemi A, Aghababaei N. (2016). Pathological narcissism, brain behavioral systems and tendency to substance abuse: The mediating role of self-control. Personality and Individual Differences, 88, 247-250.

Patron E, Messerotti Benvenuti S, Favretto G, Gasparotto R, Palomba D. (2014). 'Depression and reduced heart rate variability after cardiac surgery: The mediating role of emotion regulation". Autonomic Neuroscience. 180, 53-58.

Peter N, Alicia D. (2010). Extent and Influence of Recreational Drug Use on Men and Women Aged 15 Years and Older in South Africa. African Joumal of Drug Alcohol Studies, 9, 33-48.
Pickett SM, Bardeen JR, Orcutt HK, (2011). Experiential avoidance as a moderator of the relationship between behavioral inhibition system sensitivity and postraumatic stress symptoms. Joumal of Anxiety Disorders, 25, 1038-1045.

Pickett SM, Lodis CS, Parkhill MR, OrcuttHK. (2012). Personality and experientail avoidance :a model of anxiety sensitivity. Personality and Individual Differences, 53, 246-250.

Poythress NG, Skeem JL, Weir J, Lilienfeld SC, Douglas KS, Edens JF, Kennealy PJ. (2008). Psychometric properties of Carver and White's BIS/BAS scales in a large sample of offenders. Personality and Individual Differences, 45, 732-737

Raykov T, Marcoulides, GA. (2006). A first course in structural equation modeling. $2^{\text {th }} \mathrm{Ed}$. New Jersey: Lawrence Erlbaum Associates.

Scheres A, Sanfey AG. (2006). Individual differences in decision making: Drive and reward responsiveness affect strategic bargaining in economic games. Behavioral and Brain Function. 2: 35.

Steiger J. (2007). Understanding the limitations of global fit assessment in structural equation modeling. Personality Individual Differences; 42(5): 893-898.

Taube-Schiff M, Van Exan J, Tanaka R, Wnuk S, Hawa R, Sockalingam S. (2015). "Attachment style and emotional eating in bariatric surgery candidates: The mediating role of difficulties in emotion regulation". Eating Behaviors. 18,36-40.

Tull MT, Gratz KL, Latzman, RD, Kimbrel NA, Lejuez CW. (2010). Reinforcement sensitivity theory and emotion regulation difficulties: a multi modal investigation. Personality and Individual Differences, 49, 989-994.

Weiss NH, Forkus SR, Contractor AA, Schick MR. (2018). Difficulties regulating positive emotions and alcohol and drug misuse: A path analysis. Addictive behaviors, 84, 45-52. 